\title{
Photo-Controlled Organocatalyzed Living Radical Polymerization and Its Application to Polymer Brush Synthesis on Surface
}

\author{
Chen-Gang Wang, Feifei Li, and Atsushi Goto* \\ Division of Chemistry and Biological Chemistry, School of Physical and Mathematical \\ Sciences, Nanyang Technological University, 21 Nanyang Link, 637371 Singapore \\ *agoto@ntu.edu.sg
}

\begin{abstract}
This review briefly summarizes photo-controlled organocatalyzed living radical polymerization using alkyl iodides as initiators and organic molecules as catalysts. The polymerization was selectively controlled at desired wavelength by exploiting suitable catalysts in the $350-750 \mathrm{~nm}$ wavelength range. This range covers the whole visible region. The polymerization was applied to polymer brush synthesis on surfaces. Concentrated polymer brushes with high surface occupancy $\sigma^{*}$ (e.g., 0.37) were obtained. A patterned brush was also fabricated.
\end{abstract}

Keywords: Photochemical catalysis, Controlled radical polymerization, Organic catalysis, Polymer brushes, Surfaces

\section{Introduction}

Living radical polymerization (LRP) is a useful technique for designing polymer structures with narrow molecular weight distributions [1,2]. LRP is based on the reversible activation of a dormant species (Polymer-X) to a propagating radical (Polymer) (Scheme 1a) [3]. If the polymer chains experience a sufficiently large number of activation-deactivation cycles over the period of the polymerization time, the polymer chains are given a nearly equal chance to grow, yielding lowpolydispersity polymers. Not only thermal heating but also photo irradiation has been utilized to control CRP systems [4-19]. Photochemical stimulus is one of the most useful external stimuli that can instantly switch the polymerization "on" and "off" and can spatially trigger the polymerization at specific positions. The polymerizations are also selectively inducible in response to the irradiation wavelengths.

We have developed a new family of LRP, i.e., reversible complexation-mediated polymerization (RCMP) [20-23]. We use iodide as X (capping agent) and organic amines and organic salts as catalysts to induce the reversible activation (Scheme 1b). RCMP and our related system [24,25] are the first organocatalyzed LRP. RCMP uses no special capping agents or expensive catalysts and is amenable to a variety of functional monomers. Another important feature is that RCMP can be controlled by photo irradiation [22,23] as well as thermal heating.

(a) Reversible activation (general scheme)



(b) RCMP

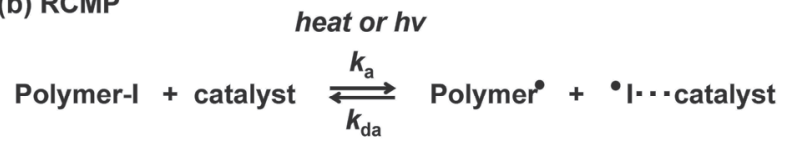

Scheme 1.

RCMP is based on a reaction of Polymer-I with a catalyst to reversibly generate Polymer (Scheme 1b). The catalyst coordinates the iodide of PolymerI to form a complex, and the C-I bond of the complex is subsequently thermally or photochemically dissociated (Scheme 2). We suppose that the catalyst operates as an antenna that 
absorbs the light and transfers the energy to cleave the $\mathrm{C}-\mathrm{I}$ bond of the complex. Photo RCMP allows us to utilize various organic catalysts with different absorption wavelengths in the range of $350-750 \mathrm{~nm}$. We can selectively control the polymerization at desired wavelengths by exploiting suitable catalysts. The feasibility over the whole visible region was unprecedented. This review briefly summarizes the previously reported polymerization performance of photo RCMP $[22,23,26]$ and also gives a new insight of the application of photo RCMP to polymer brush synthesis on surfaces.

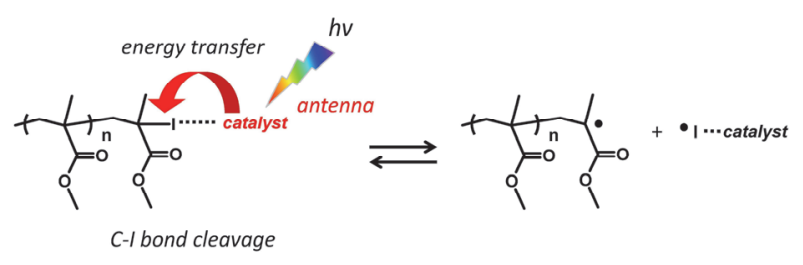

Scheme 2.

\section{Results and discussion}

\subsection{Absorption spectra}

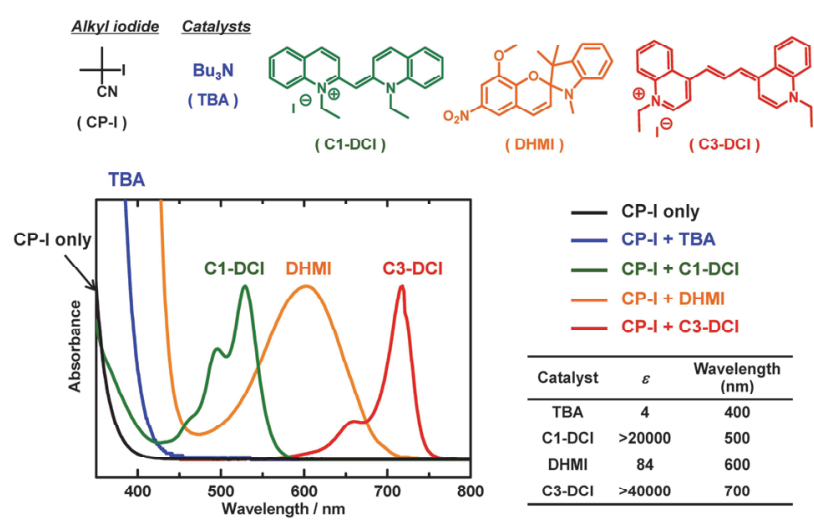

Fig. 1. Structures of CP-I and catalysts used in this study and UV-Vis-NIR spectra of CP-I (black line) and mixtures of CP-I and a catalyst in MMA. The catalysts are TBA (blue line), C1-DCI (green line), DHMI (orange line), and C3-DCI (red line). Reproduced with permission from Ref. [23] (Copyright 2015 American Chemical Society).

We used CP-I as an initiating dormant species (alkyl iodide), TBA, C1-DCI, DHMI, and C3-DCI as catalysts. Figure 1 shows their structures and abbreviations, and also the absorption spectra of CP-I only and a mixture of CP-I and a catalyst. The spectrum of CP-I (with a peak at $280 \mathrm{~nm}$ ) extended to $400 \mathrm{~nm}$ (black line). The mixture of CP-I and TBA showed a shoulder peak ranging from $350 \mathrm{~nm}$ to $450 \mathrm{~nm}$ (blue line) because of the formation of a complex of CP-I and TBA. Thus, we can use a 350$450 \mathrm{~nm}$ wavelength for the TBA system. The mixtures of CP-I with C1-DCI (green line), DHMI (orange line), and C3-DCI (red line) exhibited longer absorption wavelengths with peak maxima located at 530,600, and $720 \mathrm{~nm}$, respectively. We can use such longer wavelengths for these catalyst systems.

\subsection{Temporal control of polymerization}

We carried out a bulk polymerization of methyl methacrylate (MMA) (100 eq) with CP-I (1 eq) and TBA $(0.25 \mathrm{eq})$ irradiated at $350-450 \mathrm{~nm}$ at room temperature. Because the molar ratio of MMA to CP-I was set to 100 , the degree of polymerization (DP) expected at a $100 \%$ monomer conversion is 100. Figure 2 demonstrates temporal control of the polymerization. When the lamp was turned on, the system was switched "on" and the polymerization smoothly proceeded. When the lamp was turned off, the system was immediately switched "off" and perfectly no polymerization occurred. Also importantly, the polymerization rate was finely tunable according to the lamp power. This system is an ideal photo on-off switchable and rate-tunable system. The number-average molecular weight $\left(M_{\mathrm{n}}\right)$ and polydispersity index $\left(\mathrm{PDI}=M_{\mathrm{w}} / M_{\mathrm{n}}\right)$ were also well controlled after the very initial stage of polymerization, where $M_{\mathrm{w}}$ is the weight-average molecular weight.
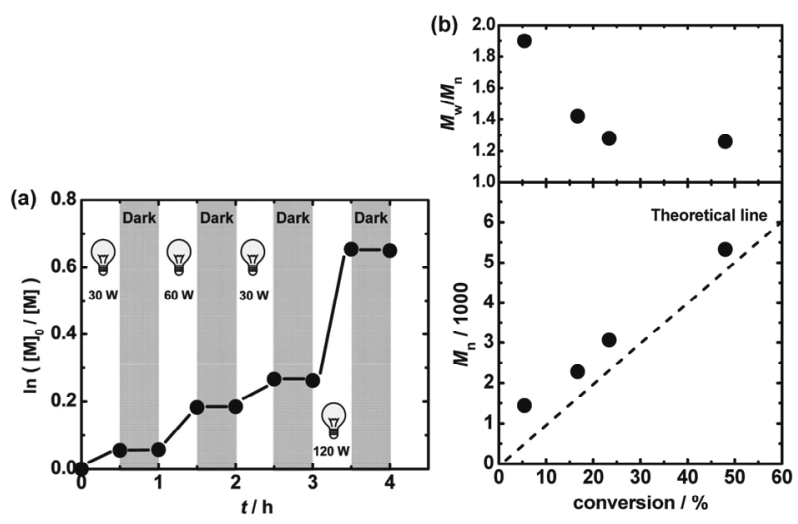

Fig. 2. Plots of (a) $\ln \left([\mathrm{M}]_{0} /[\mathrm{M}]\right)$ vs time $t$ and (b) $M_{\mathrm{n}}$ and $M_{\mathrm{w}} / M_{\mathrm{n}}$ vs monomer conversion for the MMA (M)/CPI/TBA system (ambient temperature): $[\mathrm{M}]_{0}=8000 \mathrm{mM}$; $[\mathrm{CP}-\mathrm{I}]_{0}=80 \mathrm{mM}$; $[\mathrm{TBA}]_{0}=20 \mathrm{mM}$; xenon lamp power $=$ $30 \mathrm{~W}$ (for 0-0.5 h), $60 \mathrm{~W}$ (for 1-1.5 h), $30 \mathrm{~W}$ (for 2-2.5 h) and $120 \mathrm{~W}$ (for 3-3.5 h). Reproduced with permission from Ref. [23] (Copyright 2015 American Chemical Society). 


\subsection{Polymerizations at different wavelengths}

For the extension of the feasible wavelength, we studied the polymerizations of MMA (100 equiv) containing CP-I ( 1 equiv), and TBA (0.25 equiv), C1-DCI (0.125 equiv), DHMI (0.5 equiv), or C3DCI ( 0.25 equiv) as a catalyst. Because the absorption wavelength was complementary among the four catalysts (Fig. 1), we were able to select suitable catalysts to desired wavelengths. Figure 3 demonstrates successful polymerizations at $400( \pm$ 10) $\mathrm{nm}(\mathrm{TBA}), 500( \pm 10) \mathrm{nm}(\mathrm{C} 1-\mathrm{DCI}), 600( \pm 10)$ $\mathrm{nm}(\mathrm{DHMI})$, and $700( \pm 50) \mathrm{nm}(\mathrm{C} 3-\mathrm{DCI})$.

The catalysts utilized in this study were also efficient for several functional methacrylates such as those with hydroxyl, epoxide, dimethylamino, and poly(ethylene glycol) groups. Because of the good livingness, well-defined block copolymers were also synthesized at desired wavelengths.
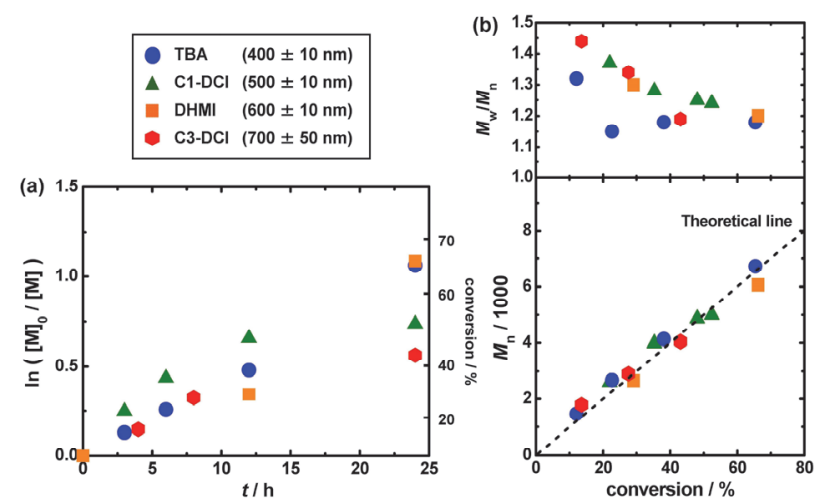

Fig. 3. Plots of (a) $\ln \left([\mathrm{M}]_{0} /[\mathrm{M}]\right)$ vs time $t$ and (b) $M_{\mathrm{n}}$ and $M_{\mathrm{w}} / M_{\mathrm{n}}$ vs conversion for the MMA/CP-I/catalyst systems (ambient temperature). $[\mathrm{M}]_{0}=8000 \mathrm{mM}$; $[\mathrm{CP}-\mathrm{I}]_{0}=80$ $\mathrm{mM}$; catalyst $_{0}=10 \mathrm{mM}(\mathrm{C} 1-\mathrm{DCI}), 40 \mathrm{mM}$ (DHMI), and $20 \mathrm{mM}$ (C3-DCI). Reproduced with permission from Ref. [23] (Copyright 2015 American Chemical Society).

\subsection{Polymer brushes on surface}

The surface of a material plays a crucial role in its mechanical, thermodynamic, chemical, optical, and electrical properties. Grafting a polymer onto a surface can dramatically change these properties; therefore, the surface grafting is important in many research areas [27,28]. Surface-initiated graft polymerization, in which polymerization is conducted from the initiator bound to the surface, is among the most effective surface modification methods. The use of LRP in surface-initiated graft polymerization enabled us to obtain a polymer brush with a high surface density. The surface occupancy can reach $40 \%\left(\sigma^{*}=0.4\right)$ [27]. This socalled concentrated polymer brush takes a highly extended chain conformation with extension up to $80 \%$ of all-trans conformation length in good solvents. Such an extended conformation affords many new properties such as high elasticity, ultralow friction, and excellent repellency of proteins and cells, which are not attainable by conventional semi-dilute and dilute brushes.

(a)

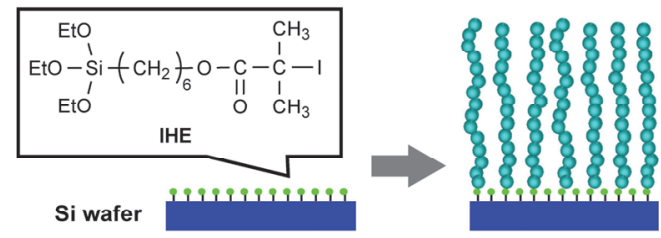

(b)

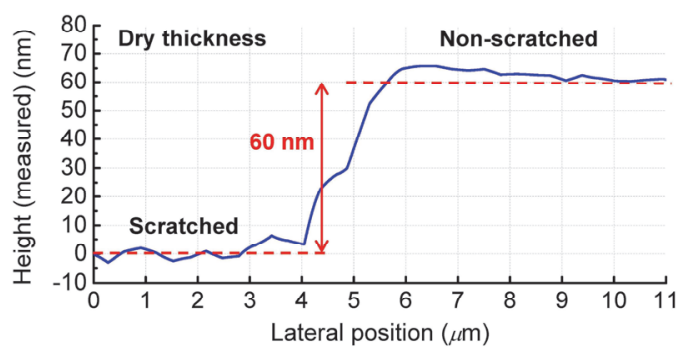

Fig. 4. Surface-initiated graft polymerization of MMA. The experimental condition is given in entry 1 in Table 1 . (a) Schematic illustration and (b) AFM height profile in the scratched and non-scratched areas of obtained brush.
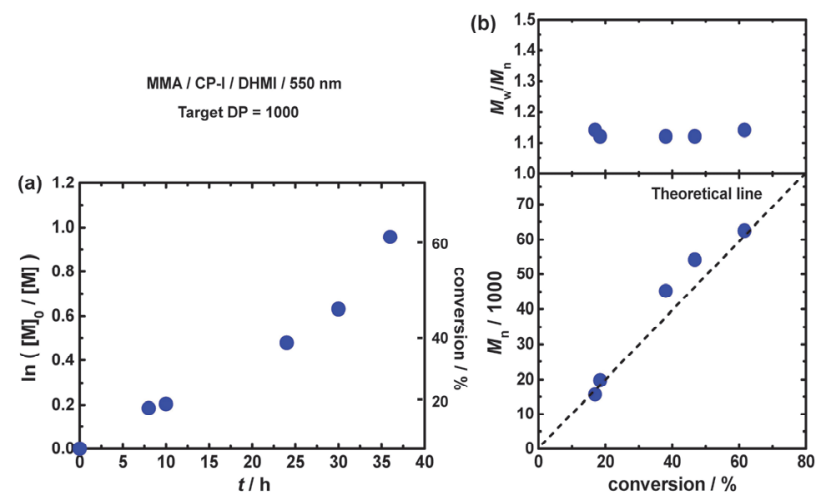

Fig. 5. Plots of (a) $\ln \left([\mathrm{M}]_{0} /[\mathrm{M}]\right)$ vs time $t$ and (b) $M_{\mathrm{n}}$ and $M_{\mathrm{w}} / M_{\mathrm{n}}$ vs conversion for the MMA/CP-I/DHMI system (ambient temperature). For experimental condition, see entry 1 in Table 1.

We applied photo RCMP to surface-initiated polymerization. We used a surface-immobilizing initiator IHE (Fig. 4) consisting of an alkyl iodide (initiating) moiety and a triethoxysilyl (TEOS) group [29]. IHE was fixed on a silicon wafer through the TEOS group. The IHE-immobilized silicon wafer was immersed in a mixture of MMA, a non-immobilized free initiator CP-I, and a catalyst DHMI and photo-irradiated at $550( \pm 10) \mathrm{nm}$ at 
room temperature for conducting polymerization (Figures 4 and 5 and Table 1 (entry 1)). The free initiator CP-I was added because its addition can improve the control over $M_{\mathrm{n}}$ and PDI of the graft polymer [27,28]. The $M_{\mathrm{n}}$ and PDI of the free polymers generated from free initiators are usually in good agreement with those of the graft polymers $[27,28]$.

To obtain a sufficiently thick brush, we targeted a high DP of 1000 at a $100 \%$ monomer conversion. The $M_{\mathrm{n}}$ of the free polymers well agreed with the theoretical values, and the PDI of the free polymers was small, 1.1-1.2, up to approximately $60 \%$ monomer conversion (Fig. 5). We obtained a polymer with $M_{\mathrm{n}}=63000$ and PDI $=1.14$ (Table 1 (entry 1)). This result demonstrates the accessibility of photo RCMP to high molecular weights.

The thickness of the brush was measured to be 60 $\mathrm{nm}$ using atomic force microscope (AFM) (Fig. 4). We scratched the brush and measured the height gap between the scratched and unscratched areas. Assuming the same $M_{\mathrm{n}}$ for the graft and free polymers, the surface density of the graft polymer was calculated to be 0.68 chains $/ \mathrm{nm}^{2}$ (the surface occupancy $\sigma^{*}$ is 0.37 ) (Table 1 (entry 1)). This density is high and located in a concentrated polymer brush region, indicating the successful controlled synthesis of a concentrated polymer brush.

\subsection{Patterned polymer brushes}

We also obtained a patterned concentrated polymer brush. We uniformly fixed IHE on a silicon wafer, covered the IHE-fixed wafer with a photo mask, and exposed a UV light to decompose IHE in the unmasked area. Figure 6 shows an optical microscope image of the surface after the polymerization (under the same polymerization condition described above (Table 1 (entry 1)). Polymer brushes were clearly observed as black lines with 20 micrometer width, in which IHE was masked and remained for initiating the polymerization.

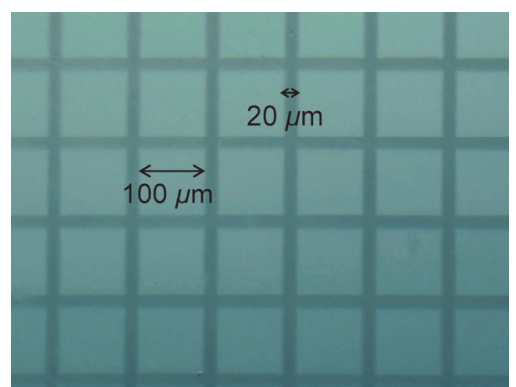

Fig. 6. An optical microscope image of a patterned polymer brush on surface. The experimental condition is given in entry 1 in Table 1 .

Table 1. Surface-Initiated Photo RCMP.

\begin{tabular}{|c|c|c|c|c|c|c|c|c|c|c|c|}
\hline entry & $\begin{array}{l}\text { Target } \\
\text { DP }\end{array}$ & catalyst & $\begin{array}{l}\text { wavelength } \\
\quad(\mathrm{nm})\end{array}$ & $\begin{array}{c}{[\mathrm{MMA}]_{0} /[\mathrm{CP}-\mathrm{I}]_{0} /} \\
{[\text { catalyst }]_{0}(\mathrm{mM})}\end{array}$ & $\begin{array}{c}t \\
(\mathrm{~h})\end{array}$ & $\begin{array}{l}\text { conv } \\
(\%)\end{array}$ & $M($ & $M_{\mathrm{w}} / M_{\mathrm{n}}$ & $\begin{array}{l}\text { Thickness } \\
\text { (nm) }\end{array}$ & $\begin{array}{l}\text { Graft density } \\
\text { (chains/nm²) }\end{array}$ & $\sigma^{*}$ \\
\hline 1 & 1000 & DHMI & $550( \pm 10)$ & $8000 / 8 / 40^{a}$ & 36 & 62 & $63000(62000)$ & 1.14 & 60 & 0.68 & 0.37 \\
\hline
\end{tabular}

${ }^{a}$ Diluted with $25 \mathrm{wt} \%$ diglyme (MMA/diglyme $=75 / 25 \mathrm{wt} \%$ ).

\section{Conclusions}

Photo RCMP is an ideal photo switchable system responding both irradiation power and wavelength that covers the whole visible region. The polymerization is compatible with functional methacrylates and can afford block copolymers. Photo RCMP is useful for synthesizing uniform and patterned polymer brushes on surfaces. The facile operation, fine response to wavelength, and applicability to a large variety of polymer designs may be greatly beneficial in various applications.

\section{References}

1. K. Matyjaszewski and M. Möller, Polymer Science: A Comprehensive Reference, Elsevier: Amsterdam, (2012).
2. N. V. Tsarevsky and B. S. Sumerlin, Fundamentals of Controlled/Living Radical Polymerization, Royal Society of Chemistry: UK (2013).

3. For a review on kinetics of LRP: A. Goto and T. Fukuda, Prog. Polym. Sci., 29 (2004) 329.

4. S. Yamago and Y. Nakamura, Polymer, 54 (2013) 981.

5. X. Pan, M. A. Tasdelen, J. Laun, T. Junkers, Y. Yagci, and K. Matyjaszewski, Prog. Polym. Sci., 62 (2016) 73.

6. C. Chen, M. Zhong, and J. A. Johnson, Chem. Rev., 116 (2016) 10167.

7. J. F. Quinn, L. Barner, C. Barner-Kowollik, E. Rizzardo, and T. P. Davis, Macromolecules, 35 (2002) 7620 .

8. A. Goto, J. C. Scaiano, and L. Maretti, 
Photochem. Photobiol. Sci., 6 (2007) 833.

9. S. Yamago, Y. Ukai, A. Matsumoto, and Y. Nakamura, J. Am. Chem. Soc., 131 (2009) 2100.

10. Y. Guillaneuf, D. Bertin, D. Gigmes, D.-L. Versace, J. Lalevée, and J.-P. Fouasseir, Macromolecules, 43 (2010) 2204.

11. Y. Kwak and K. Matyjaszewski, Macromolecules, 43 (2010) 5180.

12. M. A. Tasdelen, M. Uygen, and Y. Yagci, Macromol. Rapid Commun., 32 (2011) 58.

13. B. P. Fors and C. J. Hawker, Angew. Chem., Int. Ed., 51 (2012) 8850.

14. C. Detrembleur, D. Versace, Y. Piette, M. Hurtgen, C. Jérôme, J. Lalevée, and A. Debuigne, A. Polym. Chem., 3 (2012) 1856.

15. H. Zhou and J. A. Johnson, Angew. Chem., Int. Ed., 52 (2013) 2235.

16. N. J. Treat, H. Sprafke, J. W. Kramer, P. G. Clark, B. E. Barton, J. R. de Alaniz, B. P. Fors, and C. J. Hawker, J. Am. Chem. Soc., 136 (2014) 16096.

17. A. Wolpers and P. Vana, Macromolecules, 47 (2014) 954.

18. S. Shanmugam, J. Xu, and C. Boyer, J. Am. Chem. Soc., 137 (2015) 9174.

19. J. C. Theriot, C. H. Lim, H. Yang, M. D. Ryan, C. B. Musgrave, and G. M. Miyake, Science, 352 (2016) 1082.
20. A. Goto, T. Suzuki, H. Ohfuji, M. Tanishima, T. Fukuda, Y. Tsujii, and H. Kaji, Macromolecules, 44 (2011) 8709.

21. A. Goto, A. Ohtsuki, H. Ohfuji, M. Tanishima, and H. Kaji, J. Am. Chem. Soc., 135 (2013) 11131.

22. A. Ohtsuki, A. Goto, and H. Kaji, Macromolecules, 46 (2013) 96.

23. A. Ohtsuki, L. Lei, M. Tanishima, A. Goto, and H. Kaji, J. Am. Chem. Soc., 137 (2015) 5610.

24. A. Goto, H. Zushi, N. Hirai, T. Wakada, Y. Tsujii, and T. Fukuda, J. Am. Chem. Soc., 129 (2007) 13347.

25. A. Goto, N. Hirai, T. Wakada, K. Nagasawa, Y. Tsujii, and T. Fukuda, Macromolecules, 41 (2008) 6261.

26. A. Goto, J. Photopholym. Sci. Technol., 28 (2015) 37.

27. Y. Tsujii, K. Ohno, S. Yamamoto, A. Goto, and T. Fukuda, Adv. Polym. Sci., 197 (2006) 1.

28. P. Vana, Ed. Controlled Radical Polymerization at and From Solid Surfaces, Adv. Polym. Sci., 270 (2015) (whole volume).

29. M. Tanishima, A. Goto, L. Lei, A. Ohtsuki, H. Kaji, A. Nomura, Y. Tsujii, Y. Yamaguchi, H. Komatsu, and M. Miyamoto, Polymers, 6 (2014) 311. 